\title{
Evaluation of Serum Eosinophil-Derived Neurotoxin Level in Children with Bronchial Asthma and its Relation to Disease Severity
}

\author{
Osama Taha Amer, Mohammed Sanad Naguib, Ayman Abdulrahman Allam, Essam Monir Ibraheem Fouad \\ Department of Pediatrics, Faculty of Medicine - Zagazig University \\ *Corresponding author: Essam Monir Ibraheem Fouad, Mobile: (+20)01024683929, \\ Email: mosad8rashed@gmail.com
}

\begin{abstract}
Background: Asthma is a chronic inflammatory disease of multifactorial etiologies. The eosinophil is a major player in allergic disease. Therefore, direct measurement of eosinophilic inflammation is needed for diagnosis.

Objective: To assess Eosinophil-Derived Neurotoxin serum level in children with bronchial asthma. Also, to determine the relation of these levels to severity of bronchial asthma in children.

Patients and methods: This case control prospective study was conducted during the period from August 2018 to August 2019. This study included 85 cases (17 in each group) divided into: control, intermittent, mild, moderate and severe persistent asthma groups. This study was carried out at Pediatric Department of Zagazig University Hospitals. Results: Eosinophil-Derived Neurotoxin (EDN) concentrations were significantly increased in asthmatic children when compared to controls ( $\mathrm{p}$-value < 0.05). The current work revealed that EDN levels can be considered as a possible biomarker for asthma diagnosis $(\mathrm{PPV}=91.9 \%, \mathrm{NPV}=100 \%$, sensitivity $=100 \%$, specificity $=64.7 \%)$. The level of serum EDN was statistically higher in moderate and severe 0.832 .

Conclusion: EDN level was higher in asthmatic children than controls and correlated with asthma severity. Therefore, serum EDN can be considered as a possible biomarker for diagnosis, grading of asthma severity and the degree of airway inflammation. Serum EDN had a significant correlation with mean spirometric parameters in asthmatics. Therefore, it can reflect airway resistance in asthmatic children.
\end{abstract}

Keywords: Serum Eosinophil-Derived Neurotoxin, Bronchial asthma, Evaluation, Severity.

\section{INTRODUCTION}

Asthma is a chronic inflammatory disease of multifactorial etiologies that affects 300 million people worldwide. Initially, asthma was considered typical eosinophilic airway inflammation initiated by allergic sensitization, which results in airway hyperresponsiveness (AHR) and acute bronchoconstriction. Among asthmatic patients, severe asthma (SA) is responsible for more than $50 \%$ of the medical expense of asthma, even though it accounts for $5 \%-10 \%$ of entire asthma patients. Severe asthmatics are suffering from frequent exacerbations that contribute to progressive lung function decline and increasing burden of medical cost ${ }^{[1]}$.

The eosinophil is a major player in allergic disease. Therefore, direct measurement of eosinophilic inflammation is needed for diagnosis, treatment and monitoring of asthma. However, management decisions have traditionally been based on symptoms (nonspecific and subjective), airway function and rescue medication use. The current feeling on eosinophilic inflammation monitoring is that eosinophil counts/percentages provide only a limited understanding of the activity of these cells, whereas, the secretory activity of eosinophils (the product of the concentration of eosinophils and their propensity to release mediators) provides a more accurate and complete picture ${ }^{[2]}$.

This study aimed to assess Eosinophil-Derived Neurotoxin serum level in children with bronchial asthma and to determine the relation of these levels to severity of bronchial asthma in children.

\section{PATIENTS AND METHODS}

This case control prospective study was conducted during the period from August 2018 to August 2019. This study included 85 cases divided into 5 groups: control, intermittent, mild, moderate and severe persistent asthma (17 in each group). This study was carried out at Pediatric Department of Zagazig University Hospitals.

Design of the study: Case control prospective study. Ethical approval:

This study was ethically approved from Institutional Reviewer Board (IRB), Faculty of Medicine, Zagazig University Hospital. A written consent was obtained from every case' parent or their caregivers.

\section{Sample size:}

Assuming that mean + SD of EosinophilDerived Neurotoxin in bronchial asthma group and in control group was $73.3+59.5$ versus $31.9+22.5$ respectively. So, sample size was calculated by Open Epi program to be 85 cases (17 in each group): control, intermittent, mild, moderate and severe persistent asthma with confidence level $95 \%$ \& power of test $80 \%$. 
Target population:

Children with bronchial asthma admitted to Pediatric Department, Zagazig University.

\section{Inclusion criteria:}

Cases: all patients (5-14 years old) presented by wheezy chest and diagnosed as bronchial asthma by history, clinical picture and investigated by chest $\mathrm{x}$ ray.

Healthy control: age and sex matched healthy children.

\section{Exclusion criteria:}

1- Age less than 5 year.

2- Dehydration, malignancies \& immune compromised patients.

3- Cystic fibrosis and active pulmonary tuberculosis.

4- End stage liver or renal diseases.

5- Patient or relatives do not consent to participate in the study.

6- Health condition that would affect ability to give blood specimens.

\section{Methodology:}

All patients were subjected to the following:

A- Full history taking.

B- Meticulous general examination.

C- Local chest examination

D- Investigations:

$>$ Pulmonary function assessment: The pulmonary function tests were done by using the Jaeger Germany Spirometer.

\section{The following parameters were measured for} each subject:

1- Forced vital capacity (FVC).

2- Forced expiratory volume in the first second

(FEV1).

3- Percentage of the forced expiratory volume in the first second to the forced vital capacity (FEV1/FVC).

4- Forced expiratory flow 25-75\% (FEF 25-75\%).

5- Peak expiratory flow (PFF).
* Interpretation of Pulmonary Function Tests (PFT)

\begin{tabular}{|c|c|c|c|c|c|}
\hline PFT & $\begin{array}{l}\text { Normal } \\
\text { child }\end{array}$ & $\begin{array}{l}\text { Intermittent } \\
\text { asthma }\end{array}$ & $\begin{array}{l}\text { Mild } \\
\text { asthma }\end{array}$ & $\begin{array}{l}\text { Moderate } \\
\text { asthma }\end{array}$ & $\begin{array}{l}\text { Severe } \\
\text { asthm } \\
\text { a }\end{array}$ \\
\hline $\begin{array}{l}\mathrm{FEV}_{1} \\
\mathrm{PEF}\end{array}$ & $80-120 \%$ & $\begin{array}{l}\text { Normal } \\
\text { between } \\
\text { exacerbation } \\
>80 \%\end{array}$ & $>80 \%$ & $60-80 \%$ & $<60 \%$ \\
\hline $\begin{array}{l}\text { FEV1 } 1 \\
/ F V C\end{array}$ & $75-85 \%$ & $>80 \%$ & $>80 \%$ & $75-80 \%$ & $<60 \%$ \\
\hline
\end{tabular}

- Measurement of blood cell count.

- Measurement of serum IgE level.

- Eosinophil-Derived Neurotoxin.

\section{Statistical analysis}

Recorded data were analyzed using the statistical package for social sciences, version 20.0 (SPSS Inc., Chicago, Illinois, USA). Quantitative data were expressed as mean \pm standard deviation (SD). Qualitative data were expressed as frequency and percentage. The following tests were done:

- Independent-samples t-test of significance was used when comparing between two means.

- Chi-square $\left(\mathrm{x}^{2}\right)$ test of significance was used in order to compare proportions between two qualitative parameters.

- The confidence interval was set to $95 \%$ and the margin of error accepted was set to $5 \%$. The pvalue was considered significant as the following:

Probability (P-value)

- $\quad P$-value $\leq 0.05$ was considered significant.

- P-value $<0.001$ was considered as highly significant.

- P-value > 0.05 was considered insignificant.

\section{RESULTS}

There was no statistically significant difference between cases and controls regarding demographic data (Table 1).

There was statistically significant difference between cases and controls regarding history (Table 2).

There were statistically significant increase in EDN among cases than controls (Table 3 ).

There were statistically significant positive correlation between EDN and (BMI, S. IgE, AEC (cells $\backslash \mathrm{mm} 3$ ) and CRP. While, there were statistically significant negative correlations between EDN and FEV1, FVC and PEF. In addition, there was no statistically significant difference between EDN and other data (Table 4). 
Table (1): Comparison between Cases and Controls regarding demographic data

\begin{tabular}{|c|c|c|c|c|c|c|}
\hline & & & Cases $($ No. $=68)$ & Controls $($ No.= 17) & test & $\begin{array}{c}\text { P. } \\
\text { value }\end{array}$ \\
\hline \multirow{2}{*}{ Age } & \multirow{2}{*}{\multicolumn{2}{|c|}{$\begin{array}{c}\text { Rang } \\
\text { Mean } \pm \text { SD }\end{array}$}} & $5-13$ & $5-14$ & \multirow{2}{*}{$* 0.824$} & \multirow{2}{*}{0.412} \\
\hline & & & $8.25 \pm 2.33$ & $7.71 \pm 1.83$ & & \\
\hline \multirow{4}{*}{ Sex } & \multirow{2}{*}{ Males } & No. & 53 & 12 & \multirow{4}{*}{ \#0.409 } & \multirow{4}{*}{.5230} \\
\hline & & $\%$ & $77.9 \%$ & $70.6 \%$ & & \\
\hline & \multirow{2}{*}{ Females } & No. & 15 & 5 & & \\
\hline & & $\%$ & $22.1 \%$ & $29.4 \%$ & & \\
\hline \multirow{4}{*}{ Residence } & \multirow{2}{*}{ Urban } & No. & 49 & 11 & \multirow{4}{*}{$\# 0.354$} & \multirow{4}{*}{0.552} \\
\hline & & $\%$ & $72.1 \%$ & $64.7 \%$ & & \\
\hline & \multirow{2}{*}{ Rural } & No. & 19 & 6 & & \\
\hline & & $\%$ & $27.9 \%$ & $35.3 \%$ & & \\
\hline
\end{tabular}

Table (2): Comparison between Cases and Controls regarding History

\begin{tabular}{|c|c|c|c|c|c|c|}
\hline & & & $\begin{array}{c}\text { Cases } \\
(\text { No. }=68)\end{array}$ & $\begin{array}{l}\text { Controls } \\
\text { No. }=17)(\end{array}$ & $\mathbf{X}^{2}$ & $\begin{array}{c}P . \\
\text { value }\end{array}$ \\
\hline \multirow{8}{*}{ order of Birth } & \multirow{2}{*}{ 1st } & No. & 40 & 1 & \multirow{8}{*}{46.569} & \multirow{8}{*}{.001} \\
\hline & & $\%$ & $58.8 \%$ & $5.9 \%$ & & \\
\hline & \multirow{2}{*}{ 2nd } & No. & 23 & 2 & & \\
\hline & & $\%$ & $33.8 \%$ & $11.8 \%$ & & \\
\hline & \multirow{2}{*}{ 3rd } & No. & 5 & 10 & & \\
\hline & & $\%$ & $7.4 \%$ & $58.8 \%$ & & \\
\hline & \multirow{2}{*}{ 4th } & No. & 0 & 4 & & \\
\hline & & $\%$ & $.0 \%$ & $23.5 \%$ & & \\
\hline \multirow{4}{*}{ Consanguinity } & \multirow{2}{*}{ negative } & No. & 16 & 14 & \multirow{4}{*}{20.606} & \multirow{4}{*}{.001} \\
\hline & & $\%$ & $23.5 \%$ & $82.4 \%$ & & \\
\hline & \multirow{2}{*}{ positive } & No. & 52 & 3 & & \\
\hline & & $\%$ & $76.5 \%$ & $17.6 \%$ & & \\
\hline \multirow{4}{*}{$\begin{array}{c}\text { Family } \\
\text { Smoking }\end{array}$} & \multirow{2}{*}{ negative } & No. & 22 & 12 & \multirow{4}{*}{8.284} & \multirow{4}{*}{.004} \\
\hline & & $\%$ & $32.4 \%$ & $70.6 \%$ & & \\
\hline & \multirow{2}{*}{ positive } & No. & 46 & 5 & & \\
\hline & & $\%$ & $67.6 \%$ & $29.4 \%$ & & \\
\hline \multirow{4}{*}{$\begin{array}{c}\text { Family History } \\
\text { of Allergies }\end{array}$} & \multirow{2}{*}{ positive } & No. & 50 & 3 & \multirow{4}{*}{18.093} & \multirow{4}{*}{.001} \\
\hline & & $\%$ & $73.5 \%$ & $17.6 \%$ & & \\
\hline & \multirow{2}{*}{ negative } & No. & 18 & 14 & & \\
\hline & & $\%$ & $26.5 \%$ & $82.4 \%$ & & \\
\hline
\end{tabular}

Table (3): Comparison between Cases and Controls regarding Eosinophil-Derived Neurotoxin

\begin{tabular}{|c|c|c|c|c|c|}
\hline \multicolumn{2}{|c|}{} & $\begin{array}{c}\text { Cases } \\
\text { (No.= 68) }\end{array}$ & $\begin{array}{c}\text { Controls } \\
(\text { No.= 17) }\end{array}$ & t.test & $\begin{array}{c}\text { P. } \\
\text { value }\end{array}$ \\
\hline $\begin{array}{c}\text { Eosinophil-Derived } \\
\text { Neurotoxin } \\
(\text { EDN)(ng/ml) }\end{array}$ & Rang & $3.7-119.7$ & $0.7-2.3$ & \multirow{2}{*}{3.997} & 0.001 \\
\cline { 2 - 5 } & Mean \pm SD & $30.74 \pm 30.05$ & $1.465 \pm 0.56$ & & \\
\hline
\end{tabular}


Table (4): Correlation between Eosinophil-Derived Neurotoxin and other (clinical and laboratory data)

\begin{tabular}{|c|c|c|}
\hline \multirow{2}{*}{ Correlation } & \multicolumn{2}{|c|}{ Pearson's correlation } \\
\cline { 2 - 3 } & $\mathbf{r}$ & $\mathbf{p}$ \\
\hline Age & 0.089 & 0.468 \\
\hline Weight & 0.120 & 0.328 \\
\hline Height & 0.046 & 0.708 \\
\hline BMI & 0.282 & 0.020 \\
\hline FEV1 & $-0.713-$ & 0.001 \\
\hline FVC & $-0.729-$ & 0.001 \\
\hline PEF & $-0.649-$ & 0.001 \\
\hline S.IgE & 0.656 & 0.001 \\
\hline ALT & 0.000 & 0.999 \\
\hline AST & 0.138 & 0.262 \\
\hline Creat. & $-0.021-$ & 0.868 \\
\hline Hb & $-0.018-$ & 0.883 \\
\hline AEC(cells $\backslash m m 3)$ & 0.586 & 0.001 \\
\hline CRP & 0.403 & 0.001 \\
\hline
\end{tabular}

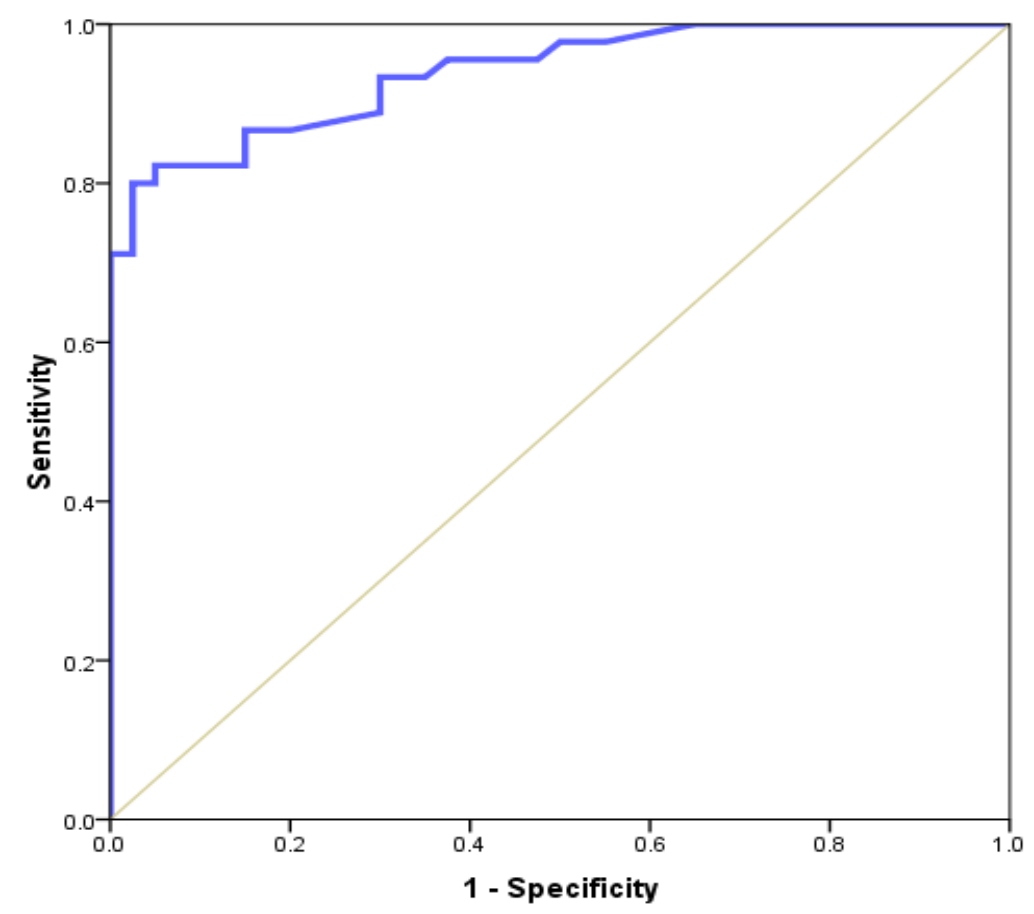

Figure (1): ROC curve for Clinical performance of EDN in asthma

Table (5): Accuracy of EDN in detection of asthma

\begin{tabular}{|l|c|c|c|c|c|}
\hline & Sensitivity & Specificity & PPV & NPV & Accuracy \\
\hline EDN & $100 \%$ & $64.7 \%$ & $91.9 \%$ & $100 \%$ & $92.94 \%$ \\
$\begin{array}{l}\text { (AUC=0.91) } \\
\text { (Cut off value=2) }\end{array}$ & & & & & \\
\hline
\end{tabular}

Table (5) and figure (1) showed that sensitivity of EDN was $100 \%$, specificity was $64.7 \%$, PPV was $91.9 \%$, NPV was $100 \%$ ) while accuracy was $92.94 \%$. 
Table (6): Comparison between intermittent asthma, mild asthma, moderate asthma and severe asthma regarding Eosinophil-Derived Neurotoxin

\begin{tabular}{|c|c|c|c|c|c|c|c|}
\hline EDN & $\begin{array}{l}\text { Intermittent } \\
\text { asthma }\end{array}$ & $\begin{array}{c}\text { Mild } \\
\text { asthma }\end{array}$ & $\begin{array}{l}\text { Moderate } \\
\text { asthma }\end{array}$ & Severe asthma & F.test & P. value & $\mathbf{P}$ \\
\hline Rang & $\begin{array}{l}3.70- \\
13.60\end{array}$ & $10-27.90$ & $\begin{array}{c}21.10- \\
36.70\end{array}$ & $\begin{array}{l}30.30- \\
119.70\end{array}$ & \multirow[t]{2}{*}{44.846} & \multirow[t]{2}{*}{0.000} & \multirow{2}{*}{$\begin{array}{l}\mathrm{P} 1=0.009 \\
\mathrm{P} 2=0.001 \\
\mathrm{P} 3=0.000 \\
\mathrm{P} 4=0.009 \\
\mathrm{P} 5=0.001 \\
\mathrm{P} 6=0.001\end{array}$} \\
\hline $\begin{array}{c}\text { Mean } \pm \\
\text { SD }\end{array}$ & $\begin{array}{c}\text { (a) } \\
6.96 \pm 1.45\end{array}$ & $\begin{array}{c}\text { (b) } \\
17.23 \pm \\
4.23\end{array}$ & $\begin{array}{c}(\mathrm{c}) \\
27.35 \pm \\
4.66\end{array}$ & $\begin{array}{c}\text { (d) } \\
71.40 \pm 4.25\end{array}$ & & & \\
\hline
\end{tabular}

P1 = between Intermittent asthma and Mild asthma, P2 = between Intermittent asthma and Moderate asthma P3 = between Intermittent asthma and Severe asthma, P4 = between Mild asthma and Moderate asthma P5 = between Mild asthma and Severe asthma $\quad$ P6 = between Moderate asthma and Severe asthma

There was statistically significant decrease in EDN among intermittent asthma than mild, moderate asthma and severe asthma. There was statistically significant increase in EDN among severe asthma than mild asthma and moderate asthma (Table 6).

\section{DISCUSSION}

In the present study, 22.10f our cases were females and $77.9 \%$ were males. It is known that childhood asthma is more common in boys than girls are. The increased risk for asthma in males during childhood is probably related to greater degree of bronchial liability in males. Airway in boys are smaller in comparison to their lung sizes compared to girls, which may contribute to increased risk of wheezing after a cold or other viral infections ${ }^{[3]}$.

In the present study, $72.1 \%$ of cases had an urban residence, while $27.9 \%$ had a rural residence. There was no statistically significant difference between asthmatics and controls as regards residence ( $\mathrm{p}$-value > 0.05). In rural areas, there is reduced atopy in farming families but there are other explanations such as greater exposure to bacterial infection or difference in diet and intestinal microflora in farming populations ${ }^{[4]}$.

Birth order was statistically significant higher in asthmatic than controls (P-value < 0.05). Birth order appeared to be a strong risk factor for allergy. Children with higher birth order had a lower risk of allergy compared to first-born. Researchers investigated whether birth order affected several immune markers that are set at birth, including a variation in the DNA of the IL13 gene, which is linked to allergic development. They found that among first-born children, the IL13 gene variant was associated with a statistically significant higher relative risk of having increased cord-blood IgE, which is an indication of increased allergic response ${ }^{[5]}$.

In our study, family smoking was reported statistically significant higher among the asthmatic children than controls. This means that exposure to tobacco smoke is one of the most consistent risk factors in the development and exacerbation of asthma. This result is in accordance with Vargas et al. ${ }^{[6]}$ who found that environmental tobacco smoke exposure has been associated with the increased use of the emergency department for acute asthma care. Moreover, these results are in agreement with Abdel Salam et al. ${ }^{[7]}$ who found that children exposed to the passive smoking (second hand smoking) at home or staging in the same place with a smoker are at a higher risk of asthma.

This study showed that, positive family history of allergies was statistically significant higher among the asthmatic children than controls. This agrees with Hassane et al. ${ }^{[8]}$ who found increase in asthma occurrence among children with a family history of allergies. Also, this result is in accordance with Magdy et $\boldsymbol{a l} .{ }^{[9]}$ who stated that positive family history of asthma was a risk factor for asthma, whereas family history of asthma is common.

This study showed that, among BA cases, positive consanguinity was higher than controls. This agrees with Inoue et al. ${ }^{[10]}$ who found that, consanguinity was present higher among BA than controls.

The current work revealed that serum Eosinophil-Derived Neurotoxin (EDN ng/ml) concentrations were significantly increased in asthmatic children when compared to controls (pvalue < 0.05). The exact mechanism of the Eosinophil-Derived Neurotoxin (EDN) in asthma pathophysiology remains unclear. Among the many mediators released during eosinophil 
activation, eosinophil granule proteins [eosinophil cationic protein (ECP), eosinophil derived neurotoxin (EDN), major basic protein, and eosinophil peroxidase] have been the most strongly implicated in the pathophysiology of asthma. Its cytotoxic effects include respiratory epithelial cell damage, whereas noncytotoxic effects include basophil histamine release and up-regulation of various receptors on respiratory epithelial cells, such as intercellular adhesion molecule (ICAM)-1, suggesting an immunomodulatory role for eosinophils through the secretion of ECP. EDN, also known as eosinophil protein X (EPX), has neurotoxic and biochemical properties similar to ECP but does not share its cytotoxicity toward respiratory epithelia ${ }^{[11]}$. This is in agreement with Kim et al. ${ }^{[12]}$ who demonstrated that there was higher serum EDN level in asthmatic when compared to controls. This agrees also with ElHalaly et $\boldsymbol{a l} .{ }^{[13]}$ who aimed to assess the clinical utility of Eosinophil-Derived Neurotoxin (EDN) and immunoglobulin E (IgE) as biomarkers for bronchial asthma evaluation and severity. They found that EDN was significantly increased in asthmatic children when compared to controls.

The current work revealed that EDN levels could be considered as a biomarker for asthma diagnosis $(\mathrm{PPV}=91.9 \%, \mathrm{NPV}=100 \%$, sensitivity $=100 \%$, specificity $=64.7 \%$ ). This agrees with Kim et al. ${ }^{[11]}$ who reported that, EDN not only for monitoring and treatment, but also for diagnosis (e.g., asthma: PPV $=93 \%, \mathrm{NPV}=54 \%$, sensitivity $=66 \%$, specificity $=89 \%$ ). Though eosinophils are important as major effector cells in asthma, eosinophil degranulation and its associated products like EDN may be even more important. It has been suggested that the secretory activity of eosinophils - a combination of the concentration of eosinophils and their tendency to release degranulation products - may be a key marker of disease activity and is more accurately measured by eosinophil degranulation products than by total eosinophil counts ${ }^{[14]}$. This agrees also with Kim $\boldsymbol{e t}$ al. ${ }^{[2]}$ who revealed that, clinical performance of EDN, sensitivity was $81.3 \%$, specificity was $87.1 \%$, positive predictive value (PPV) was $90.7 \%$, and negative predictive value (NPV) was $75.0 \%$.

In the present study, the level of serum EDN was statistically higher in moderate and severe asthmatics than the other two subgroups ( $\mathrm{p}$-value < 0.05). The mechanism that serum EDN was statistically higher in moderate and severe asthmatics than the other two subgroups may be demonstrated by Kim et al. ${ }^{[11]}$ who reported that, there were significantly more eosinophil degranulation (as measured by EDN and ECP levels) and eosinophilia (TECs) occurring in asthma patients compared to controls. All three eosinophil indices (EDN and ECP levels and TECs) were higher in the acute phase of asthma as compared to the stable phase, and all three were correlated with clinical asthma scores. However, when symptom scores were divided into mild, moderate, and severe subgroups based on severity, only significant differences in EDN levels amongst the three groups were found. These findings suggest that EDN is also a useful marker for identifying disease activity in children with asthma, and may better reflect disease severity than ECP levels or TECs. These results matches with Kim et al. ${ }^{[12]}$ who reported that serum EDN levels of children with severe asthma differed significantly from those with mild and moderate asthma indicating relation between EDN level and asthma severity. In addition, it was more sensitive than ECP for evaluation of asthma severity and bronchial hyperresponsiveness in asthmatic children. Similar results were obtained by Kim $\boldsymbol{e t}$ al. ${ }^{[15]}$ as they found that serum EDN is directly correlated with severity of asthma when study groups are categorized according to both GINA and Joseph-Bowen guidelines and it was more sensitive than eosinophil cationic protein for severity of asthma. Bousquet $\boldsymbol{e t}$ al. ${ }^{[16]}$ reported that eosinophilic inflammation of the airways was correlated with asthma severity.

In our current study, there was a significant positive correlation between asthmatic EDN level and $\mathrm{IgE}$ level ( $\mathrm{p}$-value $<0.001$ and correlation coefficient 0.832 ). This agrees with a study done by El Helaly $\boldsymbol{e t}$ al. ${ }^{[13]}$ who assessed the clinical utility of eosinophil-derived neurotoxin and $\operatorname{IgE}$ as biomarkers for bronchial asthma evaluation as regards type whether atopic vs non atopic and severity.

In the present work, there was a significant positive correlation between asthmatics EDN level and absolute eosinophilic count ( $\mathrm{p}$-value $<0.000$ and correlation coefficient 0.58 ). These results matches with Kim et al. ${ }^{[12]}$ who revealed highly significant direct correlation between EDN levels and eosinophilic count. They also demonstrated that serum EDN as a marker of eosinophilic inflammation may aid in diagnosis of asthma.

In our study, there were significant negative correlations between EDN level and pulmonary function tests (FEV1, FVC). We suggest that the inflammatory response of airways most likely influences the decrease in lung functions. Similar results were shown by Badar et al. ${ }^{[17]}$ who reflected that a rise in serum EDN was a true representative of increased airway resistance found 
in asthmatics. This also suggests that this parameter had significant diagnostic and prognostic values.

\section{CONCLUSION}

EDN level was higher in asthmatic children than in controls and was correlated with asthma severity. Therefore, serum EDN can be considered as a possible biomarker for diagnosis, grading of asthma severity and the degree of airway inflammation. Serum EDN has a significant correlation with mean spirometric parameters in asthmatics. Therefore, it can reflect airway resistance in asthmatic children.

\section{REFERENCES}

1. Yoo KH, Ahn HR, Park JK et al. (2016): Burden of respiratory disease in Korea: an observational study on allergic rhinitis, asthma, COPD, and rhinosinusitis. Allergy Asthma Immunol Res., 8: 527-534.

2. Kim CK, Callaway Z, Park JS et al. (2017): Utility of serum eosinophil-derived neurotoxin (EDN) measurement by ELISA in young children with asthma. Allergology International, 66 (1): 7074.

3. Mansour AE, Yasein YA, Ghandour A et al. (2016): Prevalence of bronchial asthma and its impact on the cognitive functions and academic achievement among preparatory school children in Damietta governorate, Egypt. J Am Sci., 10 (7): 119-127

4. Aljanabi M, Alhammash S, Waill N (2010): Risk Factors of Bronchial Ahtma in Children A Hospital Based Study. Raqi Postgraduate Medical Journal, 9 (1): 6-9.

5. Almqvist C, Olsson H, Fall T et al. (2016): Sibship and risk of asthma in a total population: A disease comparative approach. Journal of Allergy and Clinical Immunology, 138 (4): 1219-1222.

6. Vargas PA, Barry B, Sunday C et al. (2007): Exposure to environmental tobacco smoke among children presenting to the emergency department with acute asthma. Pediatr Pulmonol., 42: 646-655.
7. Abdel Salam M, Hegazy A, Adawy Z et al. (2014): Serum level of Naphthalene and 1, 2 Benzanthracene and their effect on the immunologic markers of asthma and asthma severity in children Egypt. Public Health Research, 4 (5): 166-172.

8. Hassane FM, Khatab AA, Saliem SS et al. (2015): Low magnesium concentration in erythrocytes of children with acute asthma. Menoufia Med J., 28: 477-82

9. Magdy Z, Ahmed S, Mohamed F (2009): Prevalence of bronchial asthma among Egyptian school. Egypt J Bronchol., 3 : 124-130.

10. Inoue T, Akashi K, Watanabe $M$ et al. (2016): Periostin as a biomarker for the diagnosis of pediatric asthma. Pediatr Allergy Immunol., 275: 521-526.

11. Kim CK, Callaway Z, Fletcher $R$ et al. (2010): Eosinophil-derived neurotoxin in childhood asthma: correlation with disease severity. J. Asthma, 47: 568-573.

12. Kim YJ, Kumaraswami V, Choi $E$ et al. (2005): Genetic polymorphisms of eosinophil-derived neurotoxin and eosinophil cationic protein in tropical pulmonary eosinophilia. Am J Trop Med Hyg., 73 (1): 125-130.

13. El-Helaly N, El-Wan A, Kamel Y et al. (2009): Eosinophil-Derived Neurotoxin versus Immunoglobulin $\mathrm{E}$ as Biomarkers for Evaluation of Bronchial Asthma. Journal of Biological Sciences, 9: 165-169.

14. Venge $P$ (2004): Monitoring the allergic inflammation. Allergy, 59: 26-32

15. Kim HB, Fletcher R, Choi J (2007): Eosinophilderived neurotoxin and eosinophil cationic protein levels correlate with bronchial wall thickness in children with asthma exacerbation. Pediatr Allergy Respir Dis., 17 (2): 127-136.

16. Bousquet J, Rabe K, Humbert $M$ et al. (2007): Predicting and evaluating response to omalizumab in patients with severe allergic asthma. Respir Med., 101: 1483-1492.

17. Badar A, Hussain MM, Saeed W et al. (2010): Correlation of eosinophil-derived neurotoxin with airway resistance in asthmatics. J Pak Med Assoc., 60: 97-101. 